\title{
Relações étnico-raciais e a questão da deficiência na literatura infantil brasileira: uma experiência em formação de professores
}

\begin{abstract}
Edna Martins*
Erica A. Garrutti de Lourenço**

\section{Resumo}

Diante do paradigma da educação inclusiva, a escola regular deve se organizar para acolher e oferecer condições objetivas de aprendizagem para todos os alunos. Com ênfase no como a diversidade é representada para crianças por meio da literatura infantil, este relato apresenta a experiência com a disciplina "Práticas pedagógicas programadas: Diversidade e literatura - representações da negritude e da deficiência para a infância" na formação de alunos do primeiro ano do curso de Pedagogia, da Universidade Federal de São Paulo, campus de Guarulhos. Essa disciplina se centrou no estudo de referenciais teóricos que versam sobre a diversidade e, mais especificamente, relações étnico-raciais e deficiência na literatura infantil. A experiência aponta para a importância de iniciativas voltadas ao desenvolvimento de atividades centradas na compreensão da diversidade para a formação do senso crítico na formação de professores.
\end{abstract}

Palavras-chave: formação de professores, deficiência, relações étnico-raciais.

\section{Racial-ethnic relations and the question of disability in Brazilian children's literature: an experiment in training of teachers}

\section{Abstract}

Considering the paradigm of the inclusive education, the regular school should organize itself to welcome and offer objective conditions of learning for all students. With an emphasis on how diversity is represented for children through children's literature, this report presents the experience with the subject "Pedagogical Programmed Practices: Diversity and Literature - representations of blackness and disability for children" in the formation of first year academic students of Pedagogical Course of São Paulo Federal University, Guarulhos Campus. This study focused on the discipline of theoretical frameworks that deal with the diversity and, more specifically, ethnic-racial and disability in children's literature. The experience points to the importance of initiatives aimed at developing activities focused on understanding the diversity in the formation of critical thinking in training of teachers.

Keywords: training of teachers; disability; ethnic-racial relations.

\footnotetext{
* Professora Doutora do Departamento de Educação da Universidade Federal de São Paulo (Unifesp), Guarulhos, São Paulo, Brasil.

** Professora da Universidade Federal de São Paulo (Unifesp). Doutoranda em Educação pela Universidade de São Paulo (USP), Guarulhos, São Paulo, Brasil.
} 


\section{Introdução}

O respeito à diversidade está explícito nos princípios básicos da educação inclusiva que defende uma escola para todos. Independente de condições socioeconômicas ou de classe social, de cultura ou etnia diversa, com condições de desenvolvimento variadas, todas as crianças devem ser acolhidas em escolas regulares. Dessa forma, crianças de classes sociais menos privilegiadas, crianças marginalizadas, de raça, credo ou cultura diferenciadas ou com deficiências devem fazer parte da escola que tem o dever de adaptar-se em seus meios físicos e humanos para atender às necessidades de todos, combatendo o preconceito e as atitudes de discriminação (UNESCO, 1994).

Nesse sentido, várias são as tentativas de adaptar a escola às necessidades das diferentes crianças que compõem o quociente de estudantes na rede pública e privada no Brasil. A escola deve se organizar para acolher e oferecer condições objetivas de aprendizagem para todos os alunos e, desse modo, destacam-se os princípios da educação inclusiva. Aos alunos devem ser disponibilizados os apoios extras necessários, intra ou interinstitucional, para Ihes assegurar uma educação efetiva de qualidade (BRASIL, 2008).

Não são raros os estudos que visam apontar e discutir experiências variadas de inclusão escolar e respeito à diversidade (MENDES, 2008; GOMES; SOUZA, 2011; SANTOS et al. 2011) e as condições históricas de exclusão, assim como sobre a inclusão de crianças nas escolas do país (VEIGA, 2010). No bojo dessas discussões recentes têm se reafirmado a urgência das propostas de formação de professores que visem promover de forma eficaz e comprometida o atendimento das reais necessidades da população escolar em suas condições singulares e complexas (ARAUJO et al., 2010; PLETSCH, 2009; PLETSCH; FONTES, 2006), pois há uma variedade de pesquisas que denunciam o despreparo dos professores para lidar com as necessidades educacionais especiais (BUENO, 1999; GLAT; FERREIRA, 2003; SANT'ANA, 2005).

A maioria desses trabalhos aponta apenas para a questão da inclusão de pessoas com deficiência na escola e o que temos visto majoritariamente é que, em cursos de formação de professores, omite-se ou apresenta-se de forma incipiente as discussões relacionadas às temáticas étnico-raciais e a importância do trabalho do professor nesse campo. Nesse sentido, acreditamos no que aponta Canen (1997) e Castro e Abromoway (2006) sobre o mito da democracia racial no Brasil, que cotidianamente é contestado e refutado nos vários episódios de preconceito, racismo e discriminações no interior das escolas brasileiras. Portanto, é fundamental que a questão de grupos que compõem minorias sejam discutidas para que tenhamos uma escola mais justa e para todos. Conforme Canen (1997, p. 479), a "educação e a formação de professores não podem mais ignorar esta realidade [multicultural]. Não se pode continuar em um modelo educacional que se omita perante a diversidade sociocultural da sociedade e aos preconceitos e estereótipos a ela relacionados". 
Historicamente a escola evoluiu e, nesse processo, trouxe consigo novas configurações físicas, humanas e sociais. Dentre essas mudanças, apontadas por Braslavsky (2005), estão as implicações de novos desafios educacionais para o século XXI que consistem, sobretudo, numa compreensão aprofundada sobre o sentido de "todo", em um movimento de tomada de consciência com relação à Educação como um direito humano inalienável de todos os cidadãos. $\mathrm{O}$ acesso crescente de populações e de grupos diversos que, em nossa história recente, não tinham a possibilidade de escolarizar-se nem nas séries iniciais, nos aponta para a impossibilidade de se pensar a escola apenas para "poucos" e para a urgente construção de uma escola que acolha a todos.

Essa escola cumpriria o papel de assegurar a todos, independente de circunstâncias ou particularidades, os saberes historicamente acumulados pela humanidade, coexistindo com as diferenças físicas, étnicas, sociais e culturais entre sujeitos e suas experiências. Sobre a questão da diversidade na escola, Sacristán (2006, p. 69) afirma:

Uma escola comum que satisfaça o ideal de uma educação igual para todos (o que pressupõe um currículo comum), na paisagem social das sociedades modernas, acolhendo a sujeitos muito diferentes, parece uma contradição ou algo impossível. No entanto, o direito básico desses sujeitos à educação em condições de igualdade (um ensino com conteúdos e fins comuns), obriga a aceitar o desafio de tornar compatível, na escolaridade obrigatória, um projeto válido para todos com a realidade da diversidade.

Diante das especificidades dessa nova escola que não só acolhe a diferença, mas trabalha incorporando a diversidade, o processo de formação de professores também ganha uma nova roupagem. Antes de se preocupar com a formação de um técnico ou um mero transmissor acrítico e mecânico de conhecimentos e informações, necessitamos formar um profissional preocupado em construir, junto às crianças, conhecimentos atrelados a uma prática comprometida com a apropriação da cultura e de um saber acumulado historicamente, num processo de inclusão que levará consequentemente à promoção da democratização e equidade social.

O trabalho pedagógico pautado em uma perspectiva que considere a diversidade pode encontrar na literatura infantil um caminho para a inclusão, considerando que, por seu intermédio, é possível refletir sobre vivências que favoreçam o acolhimento das diferenças.

A construção de histórias destinadas às crianças via literatura infantil é um fenômeno bastante recorrente, tal como a ideia de infância e o respeito às crianças em nossos dias. Historicamente, a literatura infantil no Brasil foi ganhando uma nova face. Gregorin Filho (2006) destaca que a literatura, de um 


\title{
Edna Martins - Erica A. Garrutti de Lourenço
}

modo geral, reflete o horizonte ideológico de seu tempo, ou seja, valores, atitudes, práticas políticas e sociais de cada época que se expressam nas mais variadas formas de obras literárias. Nessa perspectiva, constata-se em cada momento histórico a existência de "diferentes produções de sentido [...] ocasionadas pela instauração de narradores em diferentes lugares discursivos e ideológicos" (GREGORIN FILHO, 2006, p.186). Como exemplo da influência da literatura na formação das crianças, o autor cita o livro Cazuza, que publicado em 1938, é uma expressão de como os ideais de nação foram propagados no Brasil ao longo dos anos 30 .

Sobre essa questão, Ferreira (2006) acrescenta que até a década de 1960, alguns valores como a questão da obediência aos mais velhos e o patriotismo, assim como o valor dado à família, eram temas muito presentes na produção da literatura destinada à criança. Somente depois do processo de renovação da literatura infantil que, no caso brasileiro ocorreu na década de 70 , outras temáticas começaram a ser valorizadas como o senso crítico com relação à classe dominante, à criatividade e o questionamento de regras estabelecidas etc.

Com o passar do tempo, o mercado de livros infantis foi crescendo e atualmente é possível ver o grande quociente de obras que buscam aproximar cada vez mais as crianças do mundo da literatura nas mais variadas temáticas. Esse nicho mercadológico ligado à criança, encontrado pelos editores nas últimas décadas, tem propiciado a abertura para a discussão de temas como a diversidade e a diferença, tanto no Brasil como em outros países ocidentais. Sobre a questão das "diferenças" encontradas nos livros infantil, Silveira (2010, p. 2) aponta que:

\begin{abstract}
A visibilidade que tal temática adquiriu, sob roupagens diversas, desde a invenção norte-americana do 'politicamente correto', relaciona-se com discursos multiculturais, pós-coloniais, pós-estruturalistas, todos com significados, objetivos e efeitos bastante diversos, ou seja, o discurso da diversidade e da diferença espaIhou-se de forma tentacular no tecido social, alimentado pela redefinição do conceito de cultura, pelos impactos de movimentos sociais de reivindicação de direitos de grupos tradicionalmente oprimidos, pelo fim de empreendimentos colonialistas, por alguns avanços da ciência que permitiram questionar a 'naturalidade' de certas características atribuídas a uns e outros povos ou sujeitos.
\end{abstract}

Os livros infantis também oferecem para a escola, principalmente a de Educação Infantil, elementos essenciais para introduzir as crianças numa cultura letrada. O uso de obras literárias destinadas à criança pequena é indicado pelo Referencial Curricular Nacional para a Educação Infantil, salientando que 
[...] as instituições de Educação Infantil cumprem hoje, mais do que nunca, um objetivo primordial na formação de crianças que estejam aptas para viver em uma sociedade plural, democrática e em constante mudança [...] Ela deve intervir com intencionalidade educativa de modo eficiente visando possibilitar uma aprendizagem significativa e favorecer um desenvolvimento pleno, de forma a tornar essas crianças cidadãs numa sociedade democrática. (MED/SEF, 1998, p.12)

Nesse sentido, os editores lançam anualmente uma infinidade de livros com temáticas recorrentes ligadas à questão da diversidade, em que comumente se enfatizam valores como relações étnico-raciais, pluralidade cultural, questões de gênero, aceitação das diferenças físicas e intelectuais, dentre outras. Contudo, embora tenha havido várias mobilizações no sentido de envolver os agentes escolares nos processos de respeito à diversidade e ao pluralismo cultural constituinte da identidade nacional brasileira, amparadas sobretudo no âmbito do ensino por documentos como os Parâmetros Curriculares Nacionais (PCNs) e as Orientações Curriculares, na escola, de forma generalizada, estamos distantes de uma prática atrelada e comprometida com estas questões, produzindo a exclusão de grupos cujos padrões estéticos, físicos e étnico-culturais não correspondem aos padrões dominantes.

Pensando na importância da literatura infantil para o desenvolvimento de crianças pequenas e do papel dos livros destinados a esse público na escola e em outras agências socializadoras como na família, o objetivo desse texto é apresentar uma experiência de formação realizada no trabalho docente no curso de Pedagogia da Universidade Federal de São Paulo (Unifesp), que buscou analisar e compreender como a questão da diversidade é tratada em livros de literatura infantil em espaços educativos escolares como salas de leitura e bibliotecas. Buscamos aqui apresentar dados no sentido de contribuir com o fortalecimento de espaços de ensino e pesquisa pautados na experiência concreta do educador, através da disciplina "Práticas pedagógicas programadas: diversidade e literatura infantil - representações da negritude e da deficiência para a infância", oferecida para alunos de um curso de formação de professores.

Práticas pedagógicas programadas: diversidade e literatura infantil - representações da negritude e da deficiência para a infância

A disciplina Práticas pedagógicas programadas tem como objetivo a construção de espaços de aprendizagem que busquem a articulação entre os estudos teóricos de várias disciplinas e práticas pedagógicas com alunos que cursam do primeiro ao quarto semestre do curso de Pedagogia da Unifesp, além de realizar a iniciação dos estudantes ao mundo da pesquisa científica. Desse modo, sempre no início de cada semestre letivo são oferecidas algumas linhas de pesquisa para que os alunos possam fazer suas escolhas. Com uma carga horária de 40 horas, o trabalho é desenvolvido em encontros na universidade e 
também nos locais em que se propõem a realização de pesquisas de campo. Em grupos de até 10 alunos por professor orientador, o trabalho ocorre em datas preestabelecidas, alternando estudos teóricos, além de, em alguns casos, pesquisas de campo que resultam em produtos que são divulgados no final do semestre. Alguns trabalhos podem ter continuidade nos semestres seguintes. A disciplina também busca inserir os estudantes do curso de Pedagogia nos locais em que ocorrem as diversas práticas de pedagogos, levando em consideração que há uma diversidade de trajetórias profissionais que, na atualidade, pode ocorrer em outros espaços que não só os escolares, além de propiciar momentos de compreensão da realidade educacional em sua concretude e complexidade.

Uma das linhas de estudo e pesquisa oferecida no primeiro semestre, denominada "Diversidade e literatura infantil: representações da negritude e da deficiência para a infância", foi oferecida aos alunos do primeiro semestre do curso de Pedagogia em 2011 e contou com encontros presenciais e pesquisa de campo. Essa linha foi oferecida com o objetivo de introduzir, entre alunos e alunas do curso de Pedagogia, o debate sobre a diversidade nos livros de literatura infantil, dando ênfase a duas temáticas: as deficiências e as relações étnico-raciais.

Na discussão sobre esses temas referentes à diversidade, à deficiência e às relações étnico-raciais, buscamos encontrar em livros de literatura infantil elementos para a compreensão de como esses assuntos são abordados junto às crianças pequenas. A partir da introdução sobre a temática em trabaIhos teóricos - subsídios fundamentais para a compreensão do tema - houve a discussão e a possibilidade de reflexão sobre a questão das diferenças. Aos alunos foi oferecida a oportunidade de visitarem bibliotecas de instituições escolares e não escolares como, por exemplo, acervos de bibliotecas de bairros de várias regiões da Grande São Paulo e salas de leitura, construindo um breve panorama a partir do contato com várias realidades. Como parte desse trabalho, cada estudante escolheu duas obras de literatura infantil com o objetivo de analisar como a questão da diversidade pode ser vista e trabalhada com crianças da Educação Infantil.

Anterior ao início do processo de ida a campo, algumas questões foram elencadas: qual a localização de um determinado personagem numa trama? Como se dá o discurso sobre a diversidade? Como são resolvidos os conflitos? Como as relações intra e interpessoais são trabalhadas? Os livros de literatura infantil expressam a diversidade existente nas escolas? Em que medida os livros podem influenciar a desconstrução de estereótipos? Como analisar e escolher livros infantis que tratem dessa temática? Em quais momentos podese abordar essa temática com as crianças? dentre outras.

Juntamente com as discussões pautadas em textos sobre a temática, dentre eles os trabalhos de Gregorin filho (2006) e Neves (2008) sobre literatura 
infantil e de Amaral (1998) e Arboleya (2009) sobre a questão das diferenças e do negro na literatura infantil respectivamente, alguns livros destinados ao público infantil também foram lidos e discutidos a cada encontro: Por que Heloísa, de Cristiana Soares (2007), O frio pode ser quente, de Jandira Mansur (1991), Histórias da Preta, de Heloísa Pires Lima (1998); A África, meu pequeno Chaka, de Marie Sellier (2006), Os três cachimbos, de Sidonio Muralha (2001), A Centopéia sem pés, de Evaldo Miranda (2009) etc. Alguns contos clássicos, com traduções que traziam a maior originalidade e integridade das histórias como "O patinho feio" e a "Bela e a Fera" também foram trabalhados com os alunos, futuros professores.

A partir dessas leituras, passo a passo, os estudantes foram descobrindo as mensagens que cada livro poderia passar às crianças sobre as diferenças. Nesses momentos, foram discutidas questões importantes, ligadas muitas vezes à própria constituição familiar ou pessoal de cada um. Nos grupos de discussão, havia alunos negros que traziam suas questões para o restante da turma e outros que possuíam algum conhecido ou familiar com deficiência e, assim, a diversidade foi uma temática que ora era lida e ora vivida pelos alunos.

Nesse ínterim, a cada história contada e revista, os alunos foram percebendo pequenas sutilezas nos textos que poderiam cumprir o papel inverso da desconstrução do preconceito, numa linguagem e discurso que reforçavam a intolerância e a discriminação. Passo a passo, foram se atentando para a riqueza textual de algumas histórias, o desenvolvimento das narrativas, a função das ilustrações e, portanto, as máscaras da ideologia em cada singelo conto para crianças, ao demonstrarem regras impostas pela sociedade, regras essas que acabam por excluir aqueles que fogem dos padrões considerados como ideais pela sociedade.

\section{Conhecendo bibliotecas e os acervos de literatura infantil}

Após os encontros de estudo e discussão acerca do tema, os alunos organizaram-se para a atividade de campo, que constituiu na visita a uma biblioteca. Cada biblioteca foi escolhida pelos estudantes segundo a sua localização e outros critérios estabelecidos pelos próprios alunos pesquisadores. Ao todo, foram visitadas 13 bibliotecas pelos dois grupos de alunos dessa linha de pesquisa, um grupo formado por 16 alunos do vespertino e outro grupo formado por 10 alunos do noturno. Além de realizar uma breve avaliação do acervo de cada biblioteca no que diz respeito aos livros de literatura infantil com a temática pesquisada, também foi possível analisar alguns dados sobre o atendimento das bibliotecas, como os espaços reservados ao público infantil, a acessibilidade, facilidade/dificuldades em encontrar livros sobre a temática pesquisada, dentre outros aspectos.

A visita realizada em uma biblioteca municipal, da cidade de Guarulhos, por exemplo, foi agendada previamente por um grupo de alunos e, portanto, 


\title{
Edna Martins - Erica A. Garrutti de Lourenço
}

pôde ser acompanhada por um bibliotecário, que apresentou todo o espaço. Nela os alunos puderam constatar que, além de seu acervo voltado para todos os públicos, possuía também uma oficina para recuperação de livros e um espaço destinado aos usuários com deficiência visual. Nesse espaço, descobriram que havia a disponibilidade de alfabeto em braile, livros e o oferecimento de cursos que possibilitam à pessoa com deficiência visual criar uma história confeccionando seu próprio livro. Nesse mesmo espaço tomaram conhecimento de materiais específicos destinados às pessoas com deficiência, como um computador com software específico para que um indivíduo com deficiência visual possa ouvir o que realizou e uma impressora em braile para se ter acesso aos materiais. Além disso, foi possível descobrir que a biblioteca contava com um estúdio financiado com a finalidade de gravar histórias lidas para que uma pessoa com deficiência visual possa ter acesso a diversos materiais.

Sobre esta biblioteca relataram que $o$ acervo pode ser manuseado diretamente pelos usuários, a organização dos livros segue o sistema CDU; os usuários, de modo geral, podem localizar os livros utilizando terminais de consulta ou com a ajuda de um auxiliar da biblioteca. A parte pertinente à pesquisa de campo, ou seja, os livros de literatura infantil, estava toda em prateleiras mais baixas que as demais, ao lado do acervo em braile, que também possui livros infantis. Sobre a acessibilidade, foi observado que o semáforo localizado em frente à biblioteca possui um dispositivo sonoro que possibilita às pessoas com deficiência visual se orientarem no momento da travessia. Essas descobertas foram muitos instigantes para alguns alunos:

\begin{abstract}
Em relação à visita a biblioteca, fiquei surpreendida com o trabalho realizado para os deficientes visuais e todo público interessado nessa temática. Sobre os livros encontrados fiquei satisfeita com os títulos de qualidade apesar de existirem outros apenas interessados em atender o mercado sem se atentar ao que está propagando. Claro que faltam muitas obras a respeito da deficiência, mas acredito que isso está mudando. (Paula, aluna do grupo)
\end{abstract}

Na maioria das bibliotecas pesquisadas, com relação à busca pelos livros que tratassem de questões diretamente ligadas à questão da deficiência e das questões étnico-raciais, os alunos encontraram dificuldade na localização, principalmente pela falta de catalogação e de informação por parte dos funcionários. Alguns alunos relataram que precisaram investigar todo o acervo de literatura voltada à criança para descobrir alguns poucos livros sobre a temática pesquisada.

Em outros casos, os alunos puderam ter acesso a informações como o número total de livros infantis do acervo, como foi o caso de uma aluna que visitou a Biblioteca de um Centro Educacional Unificado (CEU), onde constatou um acervo total de 1445 livros, sendo 421 de literatura infanto-juvenil. Desses, apenas 52 eram relacionados ao tema proposto. 


\section{Descobrindo novas histórias nas obras escolhidas}

No trabalho de campo, cada aluno deveria escolher duas obras de literatura infantil, disponíveis em bibliotecas que tratassem da temática. Com base nas discussões em sala e na obra de Noronha (2006), foi oferecido aos estudantes um roteiro de observação que solicitava a descrição da referência selecionada, da sinopse e da caracterização das histórias, considerando os tópicos: enunciador (narrador externo ou interno), localização na constelação (protagonista ou personagem secundário), trama (aventura, policial ou vida cotidiana), narrativa (realista, fantástica ou híbrida), discurso sobre o tema específico ou não, tipo de diferença retratado, descrição de como a diferença era tratada no início, meio e final da trama e como as relações intra e interpessoais eram abordadas.

Além das obras mais conhecidas como Menina bonita do laço de fita, de Ana Maria Machado (1997), O menino marrom, de Ziraldo (2004) e Minha irmã é diferente, de Betty Ren Wright (2003), os alunos puderam ter acesso a outras obras ainda menos conhecidas como Histórias da Preta, de Heloisa Pires Lima (1998), Por que Heloisa, de Cristiana Soares (2007) e Tanto, Tanto, de Trish Cook (1997). Ao todo, realizou-se aproximadamente a análise de 25 obras de literatura infantil com a temática das relações étnico-raciais e da deficiência.

As análises foram, ao final das reuniões com os grupos, apresentadas, compartilhadas e discutidas por todos. Os alunos também realizaram, ao final da disciplina, a título de avaliação, um relatório final em grupo em que todos puderam socializar e sistematizar as impressões fundamentais de cada participante em um único documento escrito.

\section{Os relatórios escritos: momentos de reflexão}

Ao final do semestre, foi possível analisar, a partir das falas dos alunos, o quanto a temática discutida e a ida a campo haviam sido positivas para a formação de cada um dos participantes. Percebemos que a formação de professores carece do trabalho investigativo que é capaz de possibilitar um maior senso crítico, principalmente com relação ao material com o qual irão trabalhar com crianças. Essa constatação aparece na fala e também na escrita dos relatórios dos alunos da seguinte forma:

O desenvolvimento da PPP 1 acerca da temática Literatura e diversidade propiciou um importante estudo e debate que certamente cumpre um papel importante em nossa formação como educadoras e também como seres humanos. [...] As leituras realizadas ao longo do semestre possibilitaram um processo de sensibilização perante o tema diversidade, fazendo com que muitos de nós passássemos também a questionar fatos cotidianos, muitas vezes naturalizados. Ao mesmo tempo, pu- 
demos refletir mais profundamente à luz de algumas leituras que problematizam tais questões. (Relatório final do grupo)

Outros alunos, como Luana, destacaram a importância da disciplina para compreender questões que nunca haviam parado para pensar. Ela aponta que "[...] as aulas de PPP serviram para abrir nossa mente nessas questões étnico-raciais e de deficiência que antes eu não percebia tão fortemente nos livros de literatura infantil".

Enquanto os alunos faziam suas descobertas dentro e fora da universidade, em nosso trabalho de formação, nós professoras ficávamos a cada encontro ainda mais instigadas pelas temáticas e num processo de grandes descobertas nesse campo, pois fomos nos embrenhando numa "floresta" de letras e cores em bibliotecas, livrarias e feiras de livros, buscando exemplos de referências bibliográficas na área da literatura infantil que pudessem ser lidas e analisadas em grupo. Nesse caminho, os alunos também foram fazendo suas próprias imersões:

[...] pudemos ler livros e histórias que oferecemos às crianças com um olhar apurado e crítico acerca das possíveis mensagens contidas nas entrelinhas dos textos, sejam elas poéticas, promotoras de reflexão ou perpetuadoras do preconceito [...] Pudemos refletir e discutir sobre como encaramos essas diferenças, reconhecer o quanto de preconceitos temos em nós mesmas - e discutir sobre eles. (Tereza)

Nos momentos em que discutíamos de forma crítica determinada obra, enfatizávamos a importância da escolha e leitura de cada história, antes de a levarmos às crianças. Salientávamos também que não precisamos descartar obras escolhidas pelas crianças, mas devemos desenvolver a prudência de podermos discutir junto aos pequeninos aspectos que porventura são apontados nas histórias de forma inadequada, com o cuidado de não produzirmos ainda mais o olhar de preconceito ou de discriminação diante do diferente. Sobre isso, a aluna Mariane aponta:

[...] pudemos perceber que precisamos aguçar nosso olhar ao selecionarmos leituras em especial para o público infantil, já que é nessa fase que a curiosidade e a descoberta pelo novo está aflorada e devemos propiciar momentos de leitura que, além da fruição, sejam de qualidade. (Mariane)

Alguns alunos destacaram também a importância de poderem ir a campo e visitarem bibliotecas. Afirmaram que puderam realizar pontes importantes com a prática profissional na escola, como é o caso de Silvia, que já possui uma formação e trabalha em uma escola: "A visita à biblioteca me ajudou 
a pensar sobre a literatura infantil em meu cotidiano como educadora, já que analisei o acervo da escola em que trabalho e comecei a perceber limites e possibilidades, antes não notados".

Outros alunos apontaram em suas conclusões aprendizagens pontuais sobre discriminação e preconceito e a importância do trabalho com essas categorias junto às crianças pequenas:

[...] três coisas que estiveram presentes na fala de todos... primeiramente, que o entusiasmo ao descrevermos uma obra é um dos melhores indicadores para sabermos se realmente esta história vale a pena ser contada; a segunda é a de que toda criança precisa ser ensinada a não ser preconceituosa, caso isso não aconteça ela com certeza será; e a terceira, por fim, é a de que a vivência, o enfrentamento, é a melhor solução para esse tipo de problema, e para isso, é preciso que a criança não seja apresentada a apenas uma cultura, caso contrário, ela não desenvolverá a tolerância a outros povos, a outras maneiras de viver, de pensar. (Katiane)

Enfim, a maioria dos alunos participantes da disciplina avaliou que a leitura dos artigos teóricos, assim como a realização de leituras coletivas de livros de literatura infantil trouxe a possibilidade de reflexões apuradas com relação à forma como a questão das deficiências e das relações étnico-raciais tem sido tratada nos livros destinados às crianças pequenas.

\section{Considerações finais}

Além do prazer de estar em contato com contos e histórias da literatura infantil, essa experiência nos mostrou que é urgente a necessidade de trabalharmos com temáticas advindas das práticas de socialização e escolarização de crianças pequenas com professores em formação. Muitos dos alunos participantes desse trabalho vivenciaram discussões importantes como também viram na prática a importância de formarmos um maior senso crítico com relação àquilo que iremos apresentar às nossas crianças. A importância da preparação para se contar uma história ou a análise de mensagens que podem estar implícitas ou nas entrelinhas de cada inocente história mostrou-se como um elemento essencial para a reflexão e formação do professor crítico. Na maioria dos relatórios e análises individuais, os alunos relataram a assimilação desse cuidado necessário ao se apresentar um conto literário para as crianças.

Outro aspecto discutido pelo grupo foi relativo à recente tendência do mercado em produzir a "toque de caixa" materiais destinados às crianças, sem grandes preocupações ou análises sobre o que se está oferecendo. A regra parece ser construída sob a lógica capitalista que defende o acúmulo de ganhos a qualquer custo, mas que no produto final podemos notar várias inadequações. 
Outros alunos apontaram, em seus escritos, a importante descoberta que fizeram a partir da leitura de contos clássicos. Alguns relatam que, antes das discussões, acreditavam que o melhor livro para se discutir algum tema com um grupo de crianças seria aquele em que tivesse estampado em sua capa, tanto no título como na ilustração, uma menção explícita sobre a problemática a ser tratada. Contudo, descobriram que os contos clássicos podem trazer elementos valiosos para trabalhar junto às crianças determinados assuntos polêmicos ou próprios das sociedades humanas, independente do tempo em que foram escritos.

Enfim, pensar as políticas públicas de promoção de igualdade atreladas à prática cotidiana de professores representa um elemento importante para gerar novas práticas escolares com maior aceitação à diversidade e menos preconceito. É, portanto, papel da escola trabalhar conceitos, concepções e atitudes no sentido de rumar em direção a uma educação inclusiva, em que os sujeitos deixam de ser percebidos apenas como diferentes para serem concebidos em sua diversidade. A experiência da disciplina nos fez acreditar que iniciativas voltadas ao desenvolvimento de senso crítico na formação de professores são elementares para o desenvolvimento da educação brasileira.

\section{Referências}

ARAUJO, M. V. de; RUSCHE, R. J.; MOLINA, R.; CARREIRO, L. R. R. Formação de professores e inclusão escolar de pessoas com deficiência: análise de resumos de artigos na base Scielo. Rev. psicopedag. [online]. v. 27, n. 84, p. 405-416, 2010.

ARBOLEYA, V. J. Questões de Literatura infantil e afrodescendência: o poder de ação do personagem negro nas áreas de decisão da narrativa. Revista África e Africanidades, ano 1, n. 4, p. 1-9, fev. 2009.

AMARAL, L. A. Sobre crocodilos e avestruzes: falando de diferenças físicas, preconceito e sua superação. In: AQUINO, J. G. (coord.). Diferenças e preconceitos na escola: alternativas teóricas e práticas. São Paulo: Summus, 1998. p. 11-30.

BRASIL. Política Nacional da Educação Especial na Perspectiva Inclusiva. Documento elaborado pelo Grupo de Trabalho nomeado pela Portaria Ministerial $n^{\circ}$ 555, de 5 de junho de 2007, prorrogada pela Portaria no 948, de 09 de outubro de 2007, entregue ao Ministro da Educação em 07 de janeiro de 2008.

BRASLAVSKY, C. Dez fatores para uma educação de qualidade para todos no século XXI. São Paulo: Moderna; Brasília: Unesco, 2005.

BUENO, J. G. Crianças com necessidades educativas especiais, política educacional e a formação de professores: generalistas ou especialistas. Revista Brasileira de Educação Especial, Marília, v. 3. n. 5, p. 7-25, 1999. 
Relações étnico-raciais e a questão da deficiência na literatura infantil brasileira: uma experiência em formação de professores

CANEN, A. Formação de professores: diálogo das diferenças. Ensaio: Avaliação e políticas públicas em Educação, Rio de Janeiro, v. 5, n. 17, p. 477494, out./dez. 1997.

CASTRO, M. G.; ABRAMOVAY, M.. Relações raciais na escola: reprodução de desigualdades em nome da igualdade. ed. Brasília: UNESCO, 2006.

COOK, T. Tanto, tanto. Trad. Ruth Salles. São Paulo: Ática, 1997.

FERREIRA, N. S. de A. Livros infantis: uma estratégia editorial. In: FERREIRA, N. S. de A. (Org.). Livros, catálogos, revistas e sites para o universo escolar. Campinas: Mercado de Letras/Associação de Leitura do Brasil, 2006. p. 137-152.

GLAT, R.; FERREIRA, J. R., Panorama nacional da educação inclusiva no Brasil. Relatório de consultoria técnica, projeto Educação Inclusiva no Brasil. Banco Mundial, 2003.

GOMES, C. ; SOUZA, V. L. T. de. Educação, psicologia escolar e inclusão: aproximações necessárias. Rev. psicopedag. [online], v. 28, n. 86, p. 185-193, 2011.

GREGORIN FILHO, J. N. Literatura Infantil brasileira: da colonização à busca da identidade. Via Atlântica, n. 9, p. 185-194, 2006.

LIMA, H. P. Histórias da Preta. São Paulo: Companhia das Letrinhas, 1998.

MACHADO, A. M. Menina bonita do laço de fita. São Paulo: Ática, 1997.

MANSUR, J. O frio pode ser quente. São Paulo: Ática, 1991.

MENDES, E. G. Pesquisas sobre inclusão escolar: revisão da agenda de um grupo de pesquisa. Revista Eletrônica de Educação, v. 2, n. 1, p. 3-25, jun., 2008.

MIRANDA, E. A centopéia sem pés. Guarulhos: Espaço Idea, 2009.

MINISTÉRIO da Educação e do Desporto, Secretaria de Educação Fundamental. "Introdução”. Referencial curricular nacional para educação infantil. Brasília, v.1, MED/SEF, 1998.

MURALHA, S. Os três cachimbos. 2.ed. São Paulo: Global, 2001.

NEVES, S.S. de M. Discutindo a diversidade: trabalhando com livros de literatura infantil. Revista Educação em foco, Universidade Federal de Juiz de Fora (UFJF), março/agosto de 2008.

NORONHA, L. F. F. A representação da deficiência na literatura infantojuvenil nos tempos de inclusão. Dissertação (Mestrado em Distúrbios do desenvolvimento) - Universidade Presbiteriana Mackenzie, São Paulo, 2006. 
PLETSCH, M. D. A formação de professores para a educação inclusiva: legislação, diretrizes políticas e resultados de pesquisas. Educ. rev. [online]. n. 33, p. 143-156, 2009.

PLETSCH, M. D.; FONTES, R. de S. La inclusión escolar de alumnos con necesidades especiales: directrices, prácticas y resultados de la experiencia brasileña, Revista Educar: Revista de Educación, n. 37. Jalisco, México, p. 87-97, 2006.

SACRISTÁN, J. G. La reforma educativa necesaria: entre la política educativa y la práctica escolar. Madrid: Morata, 2006.

SANT'ANA, I. M. Educação Inclusiva: concepções de professores e diretores. Psicologia em Estudo, Maringá, v. 10, n. 2, p. 227-234, 2005.

SANTOS, L. H. C. dos; GRISOTTO, K. P.; RODRIGUES, D. C. B; BRUCK, I. Inclusão escolar de crianças e adolescentes com paralisia cerebral: esta é uma realidade possível para todas elas em nossos dias? Rev. paul. pediatr. [online]. v. 29, n. 3, p. 314-319, 2011.

SELLIER, M. A África, meu pequeno Chaka. São Paulo: Companhia das Letrinhas, 2006.

SILVEIRA, R. M. H.; BONIN, I. T.; RIPOLL, D. Ensinando sobre a diferença na literatura para crianças: paratextos, discurso científico e discurso multicultural. Rev. Bras. Educ., Rio de Janeiro, v. 15, n. 43, p. 98-199, Abril. 2010.

SOARES, C. Por que Heloísa? São Paulo: Companhia das Letrinhas, 2007.

VEIGA, C. G. Conflitos e tensões na produção da inclusão escolar de crianças pobres, negras e mestiças, Brasil, século XIX. Educ. rev. [online]. 2010, v. 26, n. 1, p. 263-286, 2010.

UNESCO. Declaração de Salamanca e linha de ação sobre necessidades educativas especiais. Brasília: CORDE, 1994.

WRIGHT, B. R. Minha irmã é diferente. São Paulo: Ática, 2003.

ZIRALDO. O menino marrom. São Paulo: Melhoramentos, 2004.

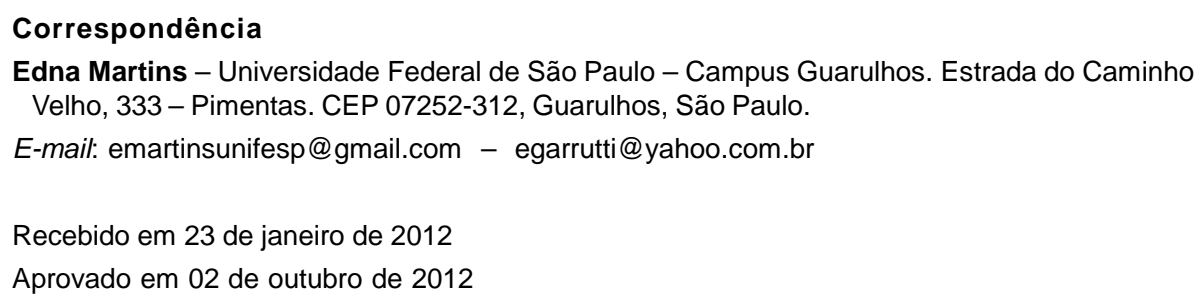

